\title{
High resolution electron microscopy of GaAs capped GaSb nanostructures
}

\author{
S. I. Molina, ${ }^{1, a)}$ A. M. Beltrán, ${ }^{1}$ T. Ben, ${ }^{1}$ P. L. Galindo, ${ }^{2}$ E. Guerrero, ${ }^{2}$ A. G. Taboada,${ }^{3}$ \\ J. M. Ripalda, ${ }^{3}$ and M. F. Chisholm ${ }^{4}$ \\ ${ }^{1}$ Departamento de Ciencia de los Materiales e I. M. y Q. I., Facultad de Ciencias, Universidad de Cádiz, \\ Campus Río San Pedro, s/n, Puerto Real, Cádiz 11510, Spain \\ ${ }^{2}$ Departamento de Lenguajes y Sistemas Informáticos, CASEM, Universidad de Cádiz, Campus Río San \\ Pedro, s/n, Puerto Real, Cádiz, 11510, Spain \\ ${ }^{3}$ Instituto de Microelectrónica de Madrid (CNM, CSIC), Isaac Newton 8, Tres Cantos, Madrid 28760, Spain \\ ${ }^{4}$ Materials Science and Technology Division, Oak Ridge National Laboratory, Oak Ridge, Tennessee \\ 37831, USA
}

(Received 2 December 2008; accepted 9 January 2009; published online 29 January 2009)

\begin{abstract}
We show in this work that GaAs capping of $2 \mathrm{ML}$ of GaSb grown by molecular beam epitaxy results in the formation of very small (with heights of about $1 \mathrm{~nm}$ ) $\mathrm{GaAs}_{x} \mathrm{Sb}_{1-x}$ nanostructures surrounded by a GaAs rich layer. This conclusion is obtained by analyzing the morphology of the $\mathrm{GaAs}_{x} \mathrm{Sb}_{1-x}$ nanostructures by high resolution scanning transmission electron microscopy in Z-contrast mode. This result shows that a significant fraction of the $\mathrm{Sb}$ atoms must segregate along the growth direction during the GaAs capping process. (C) 2009 American Institute of Physics.
\end{abstract}

[DOI: 10.1063/1.3077009]

Research on GaSb/GaAs quantum dots is a topic of increasing interest because this material has very attractive properties, such as its type-II band alignment, ${ }^{1}$ opening the possibility to fabricate new devices such as quantum information devices and memories based on quantum dots. ${ }^{2-4}$ Jiang et $a l .^{5}$ studied by atomic force microscopy (AFM) uncapped $\mathrm{GaSb}$ quantum dots grown by molecular beam epitaxy (MBE) and they found quantum dots sizes of about 10 $\mathrm{nm}$. Nevertheless, during the process of capping of the GaSb with GaAs, an important fraction of the formed quantum dots seems to disappear, probably due to the exchange reaction of $\mathrm{Sb}$ adatoms with As atoms on the GaAs surface layer. ${ }^{6,7}$ This idea is supported by the fact that very small (approximately 1-2 $\mathrm{nm}$ in size) GaAs capped $\mathrm{GaSb} / \mathrm{GaAs}$ nanostructures are observed by cross-sectional scanning tunneling microscopy on samples grown by metalorganic chemical vapor deposition at $470{ }^{\circ} \mathrm{C}$. In this work, we investigate by high resolution $Z$-contrast the nanomorphology of $\mathrm{GaAs}$ capped $\mathrm{GaSb}$ nanostructures grown at $480{ }^{\circ} \mathrm{C}$ by MBE. The analysis of the photoluminescence spectra of these nanostructures in a previous work shows evidence of a type-II band alignment, with holes strongly confined (501 meV) and electrons weakly confined (46 meV) in the electrostatic potential created by the accumulation of multiple holes inside each quantum dot under optical pumping. The quantum dot photoluminescence at $1057 \mathrm{meV}$ blueshifts as the excitation power is increased. ${ }^{8}$ Here we present a structural characterization study showing that GaAs capping of $\mathrm{GaSb}$ quantum dots results in the formation of very small (with heights of about $1 \mathrm{~nm}$ ) nanostructures at the GaAs/ $\mathrm{GaSb}$ interface.

The analyzed nanostructures were grown by solid source $\mathrm{MBE}$ at a growth rate of $0.1 \mathrm{ML} / \mathrm{s}$ at $480{ }^{\circ} \mathrm{C}$ on an $n$-type $\operatorname{GaAs}(001)$ substrate after deposition of an $n$-type GaAs buffer layer $\left(\mathrm{Si}: 1 \times 10^{18} \mathrm{~cm}^{-2}\right)$. The formation of the $\mathrm{GaSb}$ quantum dots was detected by the change in the reflection high energy electron diffraction (RHEED) pattern after depo-

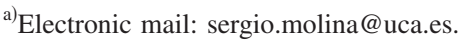

sition of $1.8 \mathrm{ML}$ of GaSb. The GaSb layer, with a nominal thickness of $2 \mathrm{ML}$, was then exposed to $\mathrm{Sb}$ flux for $20 \mathrm{~s}$ and then annealed for an additional $20 \mathrm{~s}$. The GaAs capping was done at $0.4 \mathrm{ML} / \mathrm{s}$ in two steps. In the first step, a $10 \mathrm{~nm}$ thick GaAs layer was grown at the temperature of quantum dot nucleation. In the second one, a $40 \mathrm{~nm}$ thick GaAs layer was deposited at $570{ }^{\circ} \mathrm{C}$. During the growth, the As and $\mathrm{Sb}$ beam equivalent pressures were $1.9 \times 10^{-6}$ and $7.0 \times 10^{-7} \mathrm{mbar}$, respectively. This scheme was repeated six times. In order to lower and stabilize the substrate temperature, growth was interrupted for $3 \mathrm{~min}$ between each growth cycle. The top layer was a $p$-type $300 \mathrm{~nm}$ thick GaAs:Be film grown at $580{ }^{\circ} \mathrm{C}$. Single layer samples were also grown for photoluminescence and AFM studies.

Figure 1 shows a $Z$-contrast image of the GaAs/GaSb interface obtained with the aberration-corrected scanningtransmission electron microscopy VG Microscopes HB603U microscope installed in Oak Ridge National Laboratory operating at $300 \mathrm{kV}$. The electron probe size of this microscope is less than $0.08 \mathrm{~nm}$ (Ref. 9) and the depth of field is 3-4 $\mathrm{nm} .{ }^{10}$ The image has been taken close to in-focus conditions collecting electrons scattered to angles higher than $57 \mathrm{mrad}$ using a probe forming aperture semiangle of about $22 \mathrm{mrad}$, from an area containing GaSb nanostructures, which show stronger contrast than the GaAs. This imaging mode is usually known as $Z$-contrast imaging because the intensity is strongly correlated with the $Z$ number of the analyzed atomic columns and does not suffer from contrast reversal.

The material studied here consists of GaSb nanostructures capped by GaAs epitaxially oriented on the GaAs substrate. The $\mathrm{Ga}$ and $\mathrm{As}-\mathrm{Sb}$ atomic columns are clearly resolved in the $Z$-contrast image of Fig. 1, due to the electron beam size used in our experiment that is smaller than $0.1 \mathrm{~nm}$, and therefore smaller than the distance between both atomic columns in an $\langle 110\rangle$ projection of GaAs $(0.14 \mathrm{~nm})$. In general, As-Sb columns appear brighter than Ga columns in the $Z$-contrast image because their $Z$ atomic number is higher. Higher intensities in the image will correspond to higher GaSb composition. The presence of a significant concentra- 

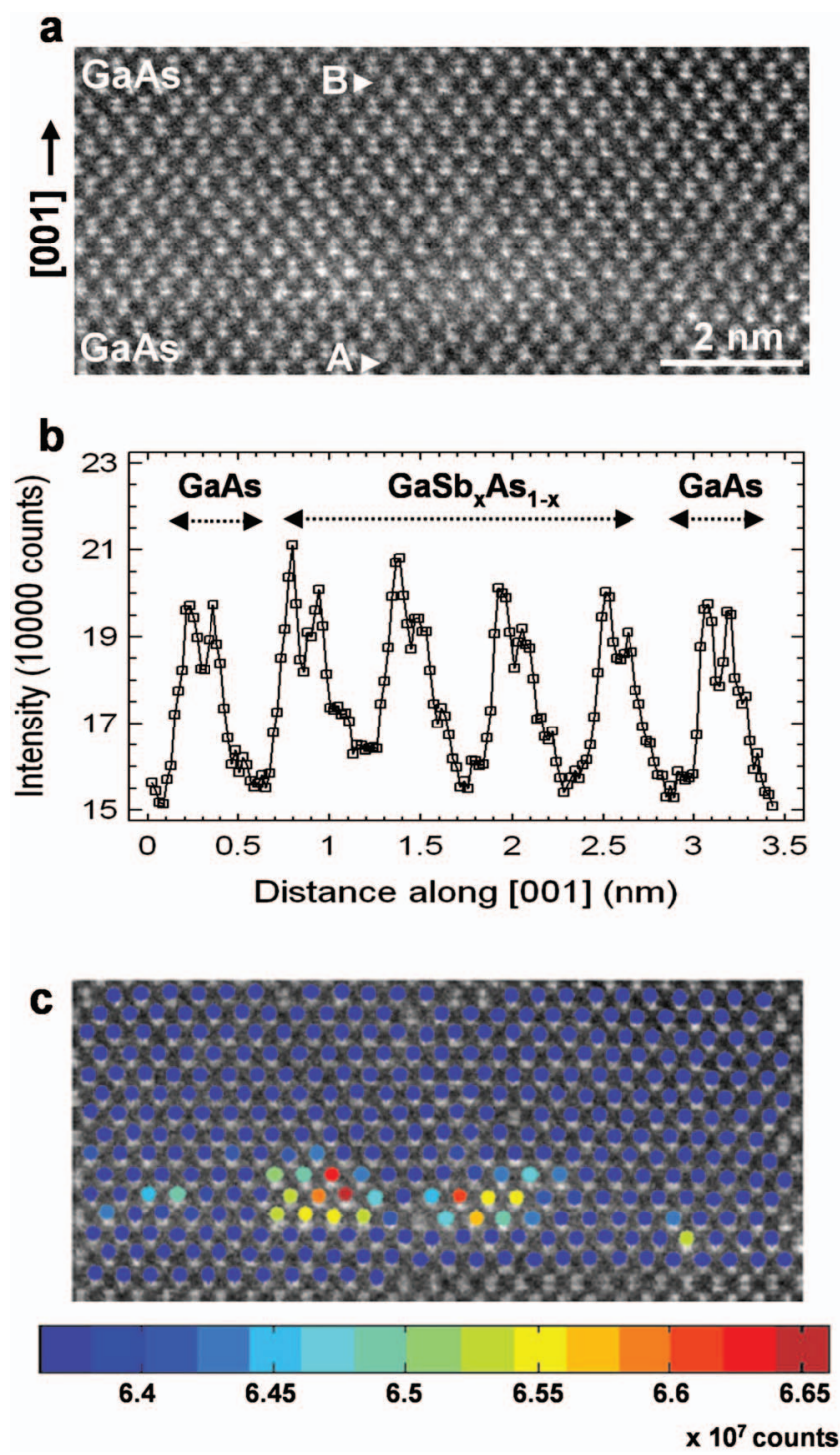

FIG. 1. (Color) (a) High resolution Z-contrast image of the $\mathrm{GaSb} / \mathrm{GaAs}$ layer. (b) Intensity profile taken from the image shown in (a) traced from $A$ to $B$ along [001]. (c) Integrated intensities for each projected unit cell superimposed on the original Z-contrast image shown in (a). Blue color corresponds to unit cells which are not statistically different from GaAs.

tion of $\mathrm{Sb}$ in an anionic column can be detected from intensity profiles as the one shown in Fig. 1(b), which has been traced along [001]. Each double-peak in this profile corresponds to atomic dumbbells of $\mathrm{Ga}$ (right peak) and $\mathrm{As}-\mathrm{Sb}$ (left peak) columns. Those peaks of a dumbbell with similar intensities correspond to $\mathrm{GaAs}\left(Z_{\mathrm{Ga}}=31, Z_{\mathrm{As}}=33\right)$, whereas higher intensities in the left peak are more likely associated with higher $\mathrm{Sb}\left(Z_{\mathrm{Sb}}=51\right)$ contents.

To analyze in more detail the $\mathrm{Sb}$ distribution in the $Z$-contrast images, we have mapped the integrated intensity in each projected unit cell, following an analogous procedure to the one explained in previous publications. ${ }^{11,12}$ In this way, the map of Fig. 1(c) has been built from the Z-contrast image of Fig. 1(a). The average integrated intensity of GaAs unit cells measured in the substrate (i.e., GaAs) region is $I_{\mathrm{GaAs}}=6.17 \times 10^{7}$ counts, with a standard deviation of $\sigma_{\mathrm{GaAs}}$ $=0.19 \times 10^{7}$ counts. Blue color columns are associated to unit cells having an integrated intensity lower than $I_{\mathrm{GaAs}}$ $+\sigma_{\mathrm{GaAs}}$, that is, to those corresponding to pure GaAs or $\mathrm{GaAsSb}$ with a $\mathrm{Sb}$ composition that is not statistically sig-

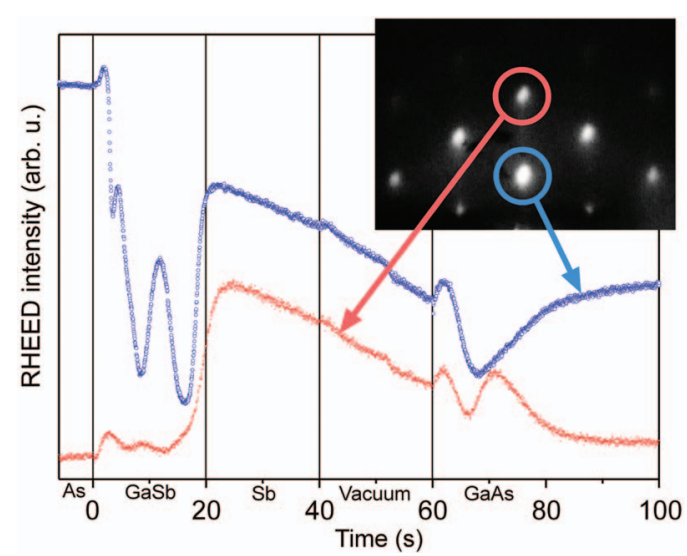

FIG. 2. (Color) RHEED pattern and oscillations acquired with the electron beam parallel to the $[\mathbf{1 1 0}]$ azimuth. Both the RHEED pattern and the threshold at $t=18 \mathrm{~s}$ are typical of quantum dot nucleation. The RHEED pattern in the inset corresponds to $t=20 \mathrm{~s}$.

nificant. $\mathrm{GaAs}_{x} \mathrm{Sb}_{1-x}$ unit cells with a significant $\mathrm{Sb}$ composition have been colored according to the count scale of the figure. Higher numbers of counts correspond to unit cells with higher $\mathrm{Sb}$ contents. These maps are very helpful to measure the lateral sizes (in the order of 1-10 nm) and heights (about $0.6-1.2 \mathrm{~nm}$ ) of the formed $\mathrm{GaAs}_{x} \mathrm{Sb}_{1-x}$ nano-objects. However, quantitative determination of $\mathrm{Sb}$ compositions is very difficult because the very small size of $\mathrm{GaAs}_{x} \mathrm{Sb}_{1-x}$ nano-objects will be surrounded by GaAs. The electron channels preferentially along the atomic columns when the electron beam is focused into the material along a zone axis (in this case a $\langle 110\rangle$ zone axis), ${ }^{13}$ and therefore the electrons collected by the high-angle annular dark field detector will have been scattered both from the $\mathrm{GaAs}_{x} \mathrm{Sb}_{1-x}$ nano-object and the surrounding GaAs material.

Given the extremely small size of the GaSb nanostructures observed by electron microscopy, a legitimate question is whether quantum dots were formed before the GaAs capping process. In Fig. 2, we present a high energy electron diffraction pattern in reflection geometry (RHEED) obtained in situ during quantum dot growth. The RHEED pattern in the inset of Fig. 2 is a transmission diffraction pattern that is typical of quantum dot formation. The spot intensity profiles in Fig. 2 have a sudden onset at $t=18 \mathrm{~s}$. Such an onset marks the critical thickness for the two-dimensional to threedimensional transition typical of Stranski-Krastanov quantum dot growth.

Figure 3 shows an AFM image of an uncapped GaSb quantum dot sample grown in the same conditions with a height profile for a representative quantum dot shown in the inset. Average lateral dimensions and height are $30 \pm 10$ and $11.2 \pm 2.0 \mathrm{~nm}$, respectively. This implies three orders of magnitude reduction in quantum dot volume during GaAs capping of GaSb quantum dots. The quantum dot dimensions decrease roughly an order of magnitude in each spatial direction.

In conclusion, the deposition by $\mathrm{MBE}$ of $2 \mathrm{ML}$ of $\mathrm{GaSb}$ on GaAs and the further GaAs capping of GaSb result in the formation of a discontinuous layer composed of $\mathrm{GaAs}_{x} \mathrm{Sb}_{1-x}$ nanostructures with heights in the order of $1 \mathrm{~nm}$ or below. GaAs capping results in three orders of magnitude volume reduction in GaSb nanostructures. This is evidence that segregation of the $\mathrm{Sb}$ must occur during the GaAs capping pro- 


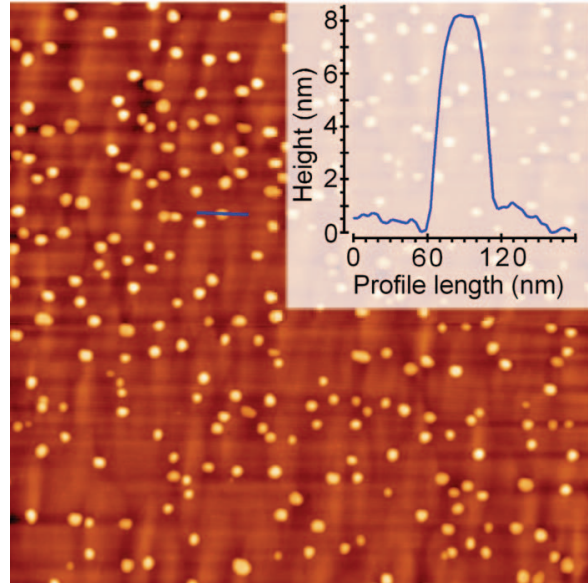

FIG. 3. (Color) AFM micrograph of GaSb quantum dots before capping. The lateral dimensions of the image are $2000 \mathrm{~nm}$ on each side. The color scale corresponds to a height range of $0-20 \mathrm{~nm}$.

cess, with the formation of a floating layer containing $\mathrm{Sb}$ during the GaAs growth.

This work was supported by the Office of Basic Energy Sciences, Division of Materials Sciences and Engineering, U.S. DOE (MFC), the SANDiE European Network of Excellence (Contract No. NMP4-CT-2004-500101), the Spanish MEC (Grant No. TEC2005-05781-C03-01 y 02, TEC2008-
06756-C03-02/TEC, NAN2004-09109-C04-01, ConsoliderIngenio 2010 CSD2006-00019), the CAM (Grant No. S 0505ESP 0200), and the Junta de Andalucía (PAI research groups TEP-120 and TIC-145; projects PAI05-TEP-00383 and TEP-03516).

${ }^{1}$ M. Geller, C. Kapteyn, L. Müller-Kirsch, R. Heiz, and D. Bimberg, Appl. Phys. Lett. 82, 2706 (2003).

${ }^{2}$ N. Yasuhara, M. Jo, Y. Sugawara, K. Kawamoto, and S. Fukatsu, J. Cryst. Growth 301-302, 718 (2007).

${ }^{3}$ C. Jiang and H. Sakaki, Physica E (Amsterdam) 32, 17 (2006).

${ }^{4}$ M.-C. Lo, S.-J. Huang, C.-P. Lee, S.-D. Lin, and S.-T. Yen, Appl. Phys. Lett. 90, 243102 (2007).

${ }^{5}$ C. Jiang, T. Kawazu, S. Kobayashi, and H. Sakaki, J. Cryst. Growth 301302, 828 (2007)

${ }^{6}$ G. Tuttle, H. Kroemer, and J. H. English, J. Appl. Phys. 67, 3032 (1990).

${ }^{7}$ T. Nakai and K. Yamaguchi, Jpn. J. Appl. Phys., Part 1 44, 3803 (2005).

${ }^{8}$ D. Alonso-Álvarez, B. Alén, J. M. García, and J. M. Ripalda, Appl. Phys. Lett. 91, 263103 (2007)

${ }^{9}$ P. D. Nellist, M. F. Chisholm, N. Dellby, O. L. Krivanek, M. F. Murfitt, Z. S. Szilagyi, A. R. Lupini, A. Borisevich, W. H. Sides, Jr., and S. J. Pennycook, Science 305, 1741 (2004).

${ }^{10}$ K. van Benthem, A. R. Lupini, M. P. Oxley, S. D. Findlay, L. J. Allen, and S. J. Pennycook, Ultramicroscopy 106, 1062 (2006).

${ }^{11}$ S. I. Molina, M. Varela, T. Ben, D. L. Sales, J. Pizarro, P. L. Galindo, D Fuster, Y. González, L. González, and S. J. Pennycook, J. Nanosci. Nanotechnol. 8, 3422 (2008).

${ }^{12}$ S. I. Molina, D. L. Sales, P. L. Galindo, D. Fuster, Y. González, B. Alén, L. González, M. Varela, and S. J. Pennycook, Ultramicroscopy 109, 172 (2009)

${ }^{13}$ E. S. Cosgriff and P. D. Nellist, Ultramicroscopy 107, 626 (2007). 